\title{
Making a Better Student Learning Experience for Virtual Learning Environment Users
}

\author{
Katie O'Connor, Liz Larkin \\ Royal College of Surgeons Ireland, Dublin, Ireland
}

\begin{abstract}
Students rely on the internet as a data source and for their educational needs; continuous changes in the learning landscape in light of technological advancements should be embraced by educators [1, 12]. Moodle is the virtual learning platform used by the Royal College of Surgeons Ireland (RCSI) to host e-learning content that supports and reinforces didactic teaching. The goal of this paper is to demonstrate that the content and interface of virtual learning environments (VLEs) impact the users' overall level of engagement with the VLEs. In 2015, we conducted a quality audit and appraisal of the RCSI's Moodle for our Faculty Department. Moodle user interface is an important element of quality control it can be influential in attracting users and imbuing confidence in using and navigating the virtual leaning environment. Between 2015 and 2018, RCSI students were surveyed regarding their Moodle user experience. In 2015, 75\% of medical students surveyed reported poor Moodle interface, because they struggled to find the information they were searching for and much of the content was outdated. Improvements were made to Moodle in light of the survey feedback. When students were resurveyed following the improvements, they found they were better able to access educational material online, as the interface was more user friendly and easier to navigate. These improvements were made with the intention to create a VLE that was better able to support, promote and manage learning amongst medical students.
\end{abstract}

\section{Introduction}

The introduction of the Internet impacted how learning and teaching is conducted [2]. Prior to the internet, information and learning resources were confined to paper-based formats. The internet reduced and removed the time delay between the need to access an educational resource and being physically able to do so. The technological advancements have meant that the present generation of learners' access and process information in a different way to previous generations. The proliferation of information technology has made an extensive volume of information readily and immediately available [3].

In the past decade, with the invention of smartphones, tablets, and laptops, the learning landscape has changed dramatically, which has allowed for an unlimited amount of information to be freely accessible, anytime and anywhere. Given these advancements, the issue is not whether we adopt new technologies, but whether we are making the most of the opportunities these technologies provide [4]. Bearing this in mind, virtual learning resources should be formatted for optimal viewing, irrespective of the device being used; be it a desktop, laptop, tablet, or smartphone.

Beyond the interface of virtual learning environments, the platform itself should not be limited to a simple repository for course content; instead it should also seek to promote online discussion and interaction. Kanuka and Garrison (2004) suggest that options for stimulating interaction and facilitating learning include giving the learner greater responsibility for their own learning, by requiring participation in collaborative projects, completing e-portfolios, and engaging in reflective writing.

\section{Virtual Learning Environment}

The evolution of technology has changed how learners access resources and how information is presented. The internet has changed the way we learn; the classroom now extends beyond the room's four walls, to create a new and different learning environment [6, 7]. Boulton [8] notes that the combination of rapid development of information technology, the incredible increase in computer literacy, and greater access to the internet provide more learning opportunities.

The concept of Technology Enhanced Learning is at the forefront of the 2030 National Strategy for Higher Education, which notes that at the higher levels 'e-learning is becoming an increasingly important part of the process of teaching, learning and research' [9]. It is vital that technology is employed to its fullest, by appropriately utilizing elearning practice and applications in order to ensure active engagement by both learners and educators [10].

The perception of learning has changed in light of technological developments and advancements [11]. Currently, learners are depending highly upon platforms, such as Moodle, as a source of information and for provision of a forum upon which the community of learners may exchange ideas and information with one another.

Technology has the potential to enhance learning and improve the efficacy and efficiency of both the 
students' learning experiences, as well as the educators' teaching experiences. These goals can be achieved by adopting a student-staff partnership approach and ensuring that changes made to the Virtual Learning Environment are in line with students and educators needs/wants.

This study examines the Virtual learning system, Moodle, as "a supportive tool for blended learning environments" [1]. Universities tend to use Moodle as an efficient way for users to access learning materials [12]. Moodle is used by the RCSI to enhance and supplement students' learning experience.

In 2015, student engagement with our Department Moodle pages was poor, with many medical students not using it at all. Our study, spanning from 2015 to 2018, considers the RCSI undergraduate medical student's use of Moodle to support their medical education. The goal for us, as educators, was to enhance the existing Moodle pages. Efforts were made to establish a Moodle that users wished to access, inhabit, and interface with.

The success of E-learning programs depends upon how well universities adopt and embed technology into their learning activities [13]. Similar to Moreno et al. [13], our findings suggest that students' perceptions of VLEs usefulness and ease of use positively influence their intention to effectively engage with Moodle. E-learning offers learners the opportunity to study in their own time and space [14]. The utilization of e-learning platforms encourages learners to move away from being solely teacher dependent to becoming self-directed learners [15].

Students are expected to take on increasing responsibility for their learning; e-learning platforms assists them in doing so by providing a curriculum, learning outcomes, and educational material that is aligned with the course curriculum.

Due to advancements in technology, some of the obstacles facing the utilization of virtual learning platforms has lessened in recent years. Historically, e-learning content creators or educators faced challenges when creating interactive, e-learning resources. However, in recent years, creation of these resources has been dramatically simplified for creators, even those with limited little technology expertise.

There are many undoubtable benefits to utilizing virtual learning platforms, yet it can be challenging to integrate new ways of learning online with more traditional classroom and didactic, lecture-based learning. Digital literacy can be a barrier to uptake of virtual learning [14]. Some virtual learning platform users may be self-taught or unskilled with information technologies, thus they may lack the necessary IT skills to utilize Moodle [13]. Lack of familiarity with Moodle or cost of Moodle training for staff and students can be an obstacle in implementation [16]. Our study found that challenges facing Moodle integration could be summarized into the following four areas:

- Technological issues

- Reluctance to change

- Lack of buy-in

- Lack of budget and staff resources

The literature review revealed that, despite technological advancements, there remain significant barriers to e-learning. In a diversified student population, there are many different ways in which students learn; this can pose a challenge for educators trying to accommodate multiple learning styles and differing types of learners.

Yates [17] identified barriers to e-learning, namely the cost associated with implementing new technologies, technical training, educator skepticism, and student misconceptions, along with the challenges of operating in a constantly changing technological environment.

Lohman [18] added to the list of educational barriers with the lack of access to learning resources as well. Bates [19] stated that a lack of adequate technical support is an obstacle for educators seeking to embed multimedia and virtual learning.

Rezabek [20] categorized barriers as being dispositional, situational, or institutional barriers. Dispositional barriers can result from an individual's learning style, attitude, and motivation along with learners' situational backgrounds. It is essential that institutional barriers be considered before implementation, such as institution's investment into e-learning.

\section{Aims and objectives}

The purpose of this research was to investigate if Moodle can be used more effectively, to facilitate Moodle use, and to assess if Moodle, as an educational tool, is being fully utilized to support learning and teaching at RCSI. With the ultimate goal of improving the students' learning experience.

This research was carried out in 2015 to 2018 and it aimed to:

- Identify issues with the existing VLE

- Implement constructive changes

- Monitor reaction to changes via student engagement and satisfaction

- Continue to promote, review and make improvements going forward.

The aim of this research was to explore if suggested Moodle modifications would positively affect learners' engagement with Moodle and improve students' satisfaction. We looked at 
effective ways of using an e-learning platform and ways to better support learning and teaching online.

\section{Methods}

The 2015 Moodle pages were reviewed in terms of its system, service, and content quality. Monitoring and interpreting the activities of users highlighted the areas of the department's Moodle pages that needed to be addressed and adjusted. The available knowledge regarding users was acted upon to better "facilitate the learning process" [15].

Our study utilized three different strands of data collection. Firstly, Moodle analytics were reviewed to establish the frequency of Moodle page visits, the duration of the visits, and the depth of engagement.

Secondly, meetings with educators and the wider RCSI academic department faculty provided insight from stakeholders of their Moodle experience to date. Annually, 330 RCSI undergraduate medical students were enrolled on the department's Moodle pages. They were invited to complete a Moodle feedback survey.

Thirdly, students who already had access to Moodle were asked for their feedback on the department's Moodle pages, both before and Moodle improvements.

Students were surveyed $(\mathrm{n}=330)$ and stakeholder meetings $(n=20)$ were conducted in order to discuss and better understand our learners, their learning needs, and how they learn. Moodle user reports, generated by the e-learning platform, indicated changes from month-to-month and year-to-year in users' frequency and duration online.

The questionnaire method was chosen for the following reasons, as outlined by Creswell [21]:

- Cost

- Convenience

- Data availability

Participants were advised of the anonymous and voluntary nature of the survey, as well as, being able to opt out at any stage. Medical students were asked to complete a 2-page, hardcopy, anonymized survey which focused on questions regarding these 5 main areas:

1) Content and delivery of problem-based learning;

2) Overall experience and learning experience;

3) Suggestions on how to improve the teaching programme;

4) Analysis of peer led teaching;

5) Use of VLE.

Survey answer options ranged from 'Extremely satisfied' to 'Extremely dissatisfied' and were captured using a 5-point Likert scale.
A series of targeted annual changes were made to the Moodle pages to enable us to gauge how these changes were received by students and educators. Moodle users were invited to give feedback via surveys and stakeholder meetings. Moodle analytics reports were also utilized to indicate how the Moodle changes were received by users. Student and educator unfamiliarity with fundamental Moodle function and design can pose an obstacle for user engagement [22]. Thus, efforts were made to minimize these potential barriers to user uptake.

Barzegar et al. [22] note that students spend a large proportion of time attempting to familiarize themselves with virtual learning systems and their layouts. In order to minimize the time spent by students in this endeavor, the students received a Moodle user talk during orientation. This talk highlights the changes made to Moodle, presents the different Moodle features, and details the e-content materials. This talk demonstrated how to use and navigate Moodle and outlined the different types of Moodle assessments embedded within the programme.

Haber and Mills [23] recognize that when making changes to teaching delivery, we must ensure that adequate support is given to faculty. We acknowledge that it was crucial to have a clear vision and a strategic plan for moving from the traditional classroom to more a more blended programme. We aimed to integrate further e-learning into the course and provided orientation courses to staff in order to communicate how and why we sought to change the manner in which we were using Moodle.

During the implementation of Moodle improvements, we were mindful of the following:

- The need for a degree of technical expertise among content creators, educators, other staff, and students

- The requirement to provide social interaction for Moodle users via Moodle forums so that engagement is promoted

- Staff may desire compensation for the time they spend on Moodle

- Staff may view technology as a threat and maybe reluctant to embrace it

- Students must have access to Moodle

- Students would require Moodle support services

These aspects were addressed by providing Moodle training for staff and students. Moodle forums and chatrooms were embedded in the new pages to foster and monitor user interaction. Staff were not required to commit additional work hours to Moodle as the Moodle Department manager dealt with any additional work stemming from the Moodle users. 
In summary the followings three data techniques were utilized:

1) Moodle analytics was used to establish

- Engagement with the VLE

- Number of times the VLE was accessed

- Number of pages and duration of access

2) Quantitative and qualitative data collected via:

- Stakeholder meetings with educators

- Questionnaires which gathered student feedback

3) Implementation

- Stakeholder and student feedback was used to make Moodle changes

- Suggested major changes were piloted before proceeding with a wider large-scale roll-out of those changes

- Incremental Moodle changes were made as part of our annual Moodle review.

\section{Discussion}

Prior to carrying out the stakeholder meetings, we expected the following issues to be highlighted regarding educators' engagement with Moodle at that time:

- That lecturers would report that they do not use Moodle to its fullest potential.

- Students in computer teaching sessions optimize the usage of Moodle more than other students.

- Educators and students do not make full use of the resources on Moodle because they are unaware of the resources available.

This feedback was reported by educators and by students in both the stakeholder meetings and in the survey findings. Anecdotally, these three aspects had been reported throughout the years, thus we were not surprised with the feedback given in relation to the usability of Moodle.

Moodle improvements were made with the intention to create a virtual learning environment that was better able to support, promote, and manage learning amongst medical students. Moodle allowed students to practice self-directed learning and they were able to control their own pace of learning online $[3 ; 4]$.

The improved Moodle mobility and functionality facilitates peer and tutor interaction, as well as improved engagement though it also introduces the need to support faculty when using new technology.

\subsection{Feedback and feedforward}

For this study, feedback and feedforward evaluation was used. These evaluations tend to be utilized to assist students in their preparation for assessments but can also aid with quality improvements in respect to e-learning environments, which in our case, was the rational for application [18].

A feedback survey was created in order to establish what data was available to date regarding Moodle usage and the Moodle experience from a student perspective [18]. Students' feedback revealed that aspects of Moodle could be improved upon. We sought to learn from the existing negative and positive aspects of the 2015 version of Moodle and used this information to make amendments to the department's pages.

Advice given by students, via survey, and staff, via stakeholder meetings, on improvements for Moodle was fed forward to create an e-learning environment that better catered to the needs of students. This feedback feedforward process was facilitated by ongoing engagement and communication with students and staff.

The teaching and learning approaches that were introduced on the Moodle pages were then also utilized in the physical classroom setting. Case Based Discussions (CBD) and Problem Based Learning (PBL) were prominent means of teaching utilized on the Moodle pages, the physical classroom lecturing didactic teaching sessions also embraced this case-based approach to teaching. This change in teaching approach complimented the improvements which had been made to Moodle.

Case based discussions encourage higher order thinking. Ferreri and O'Connor [25] note that the use of cases aid student acquisition of proficiencies in communication, problem solving, and interpersonal skills. This approach simulates discussion, as the cases do not present with a single, clear solution.

The Moodle revamp presented cases and problem-based learning from different perspectives, and used podcasts and videos to explore patients', nurses', doctors', and students' perspectives on learning cases. Kok (2010) notes that detailing a multiplicity of perspectives can promote higher order learning.

\subsection{Identifying issues and implementing change}

Re-energizing learning and teaching approaches, and ensuring constructive alignment were at the core of undertaking this Moodle revamp. Our intentions with all improvements to Moodle were to create opportunities afforded by Technology Enhanced Learning (TEL). In order to achieve effective and aligned integration of learning resources, regular reviews of Moodle were carried out and feedback was sought to ascertain students' feelings and opinions regarding the current state of Moodle.

A five-step approach was taken to identify issues with our department's 2015 RCSI Moodle pages. In the coming page, we shall outline the steps which we implemented, these steps which were applied to the 
Moodle revamp can be summarized by the phrase 'identify, change, monitor, sustain and promote'.

\section{1) Identifying issues}

We established if the 2015 RCSI Moodle pages were meeting and supporting students' learning needs. We identified means of improving student engagement on Moodle. Moodle analytics were utilized to identify the frequency and duration of student Moodle engagement, staff input and student feedback on Moodle was sought. We conducted a brief literature review. Our study's findings were consistent with the wider medical education literature.

\section{2) Introducing change}

Staff agreed upon the suggested changes that could be made to Moodle to improve engagement. We acted on those recommendations and implemented the changes. Students outlined learning elements and features which they wished to be included in the Moodle revamp.

\section{3) Monitoring reaction to changes}

We continued gathering student feedback at fixed intervals between 2016 and 2018 to see if the changes made resulted in improved student engagement with Moodle. Following Moodle improvements in 2016, 2017 and 2018, the frequency of student engagement was monitored. Moodle data on how often and how many students log into our programme Moodle pages each month over the years were reviewed.

Content engagement was gauged by monitoring the areas of Moodle which are most frequently viewed by students and which content were viewed for long periods of time.

\section{4) Sustaining change}

Annually the student survey feedback Moodle findings were reviewed along with Moodle user engagement reports which indicated how often and how many students log into Moodle; and what items they view most whilst there. Content which fall into this classification was interpreted as being of interest to students.

Data collected was utilized to make informed additional alternations to the revamped Moodle pages. In the summer of 2016 and again in 2017 and 2018, additional amendments were made to Moodle, using the same process of feedback-feedforward.

\section{5) Promoting Moodle improvements in other departments}

Other RCSI departments have utilized our Moodle layout as a template for their own Moodle improvement. These departments have also noted an improved in student engagement and satisfaction however for these results to be sustainable long-term Moodle must be maintained and updated on a regular basis in order to stay a breast with new technological advancements and to ensure up-to-date content.

\subsection{Flipping the classroom}

Much of the improvement made to our Moodle pages between 2016 and 2018 along with the subsequent movement to case and problem-based learning has aided us in moving towards a flipped classroom setting. Flipping the classroom is when students review print, audio or video based material prior to a lecture or teaching session in order for the classroom setting to focus more on the active learning processes and promote students to apply their knowledge to problem solving and the discussion of case based scenarios [26]. Admittedly as a Department we are not yet in the position to apply the necessary steps to fully 'flip' our medical classroom but with the Moodle improvements we are now better positioned in the future to 'flip' the classroom, if deemed appropriate.

\section{Results}

Feedback in 2015 showed student engagement and satisfaction was poor. To address this problem, students were surveyed and asked to indicate aspects of the e-learning environment that they liked and areas which could be improved upon.

In 2015 initial feedback showed high levels of dissatisfaction with the VLE. The 2015/2016 survey findings showed that students viewed Moodle as portraying static content, with Moodle pages containing mostly teaching slides and applying a 'one-size fits-all attitude' because it tended to cater to primarily linguistic learners [14]. There are different types of learners and the traditional means of delivering medical lectures may not appeal to all learners. The Moodle changes focused on enhancing learnability and we achieved this by creating consistent content that catered to different learning styles [27].

2015/2016 qualitative student feedback on Moodle can be summarized into the following general student comments:

- Lack of lectures on Moodle

- Moodle is a mess

- Moodle is unstructured and disorganized 
- Too many Moodle files that don't cover topic well

After the 2016 Moodle revamp, 65\% of students rated their VLE experience as excellent or good. Moodle engagement levels increased following the enhancements and content updates. Following the Moodle revamp in 2017 students' following qualitative Moodle feedback was more positive:

- Moodle is accessible

- Good layout and aesthetic pleasing

- Well organized grouping of sections

- Good content

- Useful links

Between 2016 and 2018, usability of the Moodle pages was enhanced "by making web pages simple to navigate and intuitively organized" in order to 'help users find information with ease' [28]. Compared to 2016, there was a $65 \%$ increase in the number of student visits in 2017. From 2017 to 2018, there was a further $14 \%$ increase in student engagement.

The study's findings showed that the modifications made to Moodle demonstrated positive results in students' frequency in which they utilized Moodle; the length of time they spent on it and their level of satisfaction interacting with it increased.

By 2018 there was a 79\% increase in the number of student visits following implementation of these main improvements which were made to the virtual learning platform:

\section{- Usability}

Making the e-learning platform more user friendly in its layout and organization of material.

\section{- Compatibility}

Improving compatibility across different devices and ensure a consistent interface so that Moodle can be accessed on mobile devices anytime, anywhere.

\section{- Diversity}

Creating multimedia content allowed users to select the media options that they felt best suit their learning style or approach.

\section{- Medical educational videos}

Medical education videos were created to demonstrate how doctors should conduct a physical exam; take patient history; how doctors should communicate and interact with patients and their parents. Creation of educational videos provided flexibility for students and enhance their learning. The videos displayed a standardized approach. The videos provided clarity and consistency (for educators and students).
Students cited the following benefits regarding the videos which allowed them to see the correct technique so that they can compare their own approach and identify any mistakes students may be making and rectify them. Students are able to replay the videos an unlimited amount of times so students can repeat their practices and reinforce the correct technique.

Our survey findings showed that students desired a wider array of multimedia resources which would permit users to select the media options that best suits their preferred means and media of learning.

\section{- $\quad$ Self-directed learning}

E-learning requires students to take more responsibility for their own learning. Gaining these independent learning skills early on will aid the students in becoming lifelong self-directed learners through continued medical education [15].

\subsection{Outcomes}

Positive outcomes stemming from the Moodle revamp were identified in this study's survey findings as users reported that Moodle was now viewed as a 'one stop shop' as all information was now in one place. Moodle can be accessed on the go and its accessibility had improved as students could download learning material that can be access before, during and after teaching sessions. The Moodle content was also made to be compatible with different platforms (mobiles; Firefox; chrome; IE).

Though the feedback was predominantly positive, following the Moodle revamp users were asked to identify any potential drawbacks or negative outcomes related to the Moodle changes. In the survey findings a small number of students noted that increased reliance on Moodle as a teaching/ learning tool may further limit student-lecturer engagement time. In response to these concerns' students were assured that Moodle teaching did not seek to replace physical teaching sessions, instead Moodle was being utilized to supplement, support and reinforce classroom teaching.

Some students reported that independent studies can result in a feeling of isolation and insecurity. The concerns voiced regarding student welfare were addressed by providing Moodle support services and ensuring that the Moodle education manager was on Moodle daily in the event students required assistance or welfare support. In addition to the very small number of negative feedback from students regarding the Moodle improvement, educators also voiced reservations following the Moodle revamp. Lecturers expressed concerns about the Department's long-term ability to maintain the quality and quantity of course content covered on Moodle. The Moodle changes limited educators' options for teaching strategies because the content had to be in line with 
the e-learning content on Moodle. For one or two Moodle assessments that needed to reviewed lecturers in order for them to provide feedback, educators noted that they sometimes felt under pressure to provide timely feedback for students for these assessments because the assessment process was also being monitored by the Department Moodle manager.

\subsection{Recommendations}

Data collection generated qualitative and quantitative findings which highlighted that students required individual assessment feedback which is of a high quality and given in a timely manner. As part of the Moodle revamp the addition of formative and summative Moodle assessment allowed students to monitor their own ongoing progression throughout the course however students commented that a rubric should be provided to allow for greater transparency of the grading system.

\subsection{Reflection on results}

Our study's findings concur with Kok's paper [3] on the use of digital learning tools for reflective thinking, which concluded that when used appropriately, interactive technologies can promote collaborative discussion and encourage students to engage in analyzing and critically evaluating cases and problems.

Virtual learning environments can enhance students' learning process, promote higher order thinking, and expand their skillsets. If such skills are encouraged by intuitive Moodle pages, they can be further built upon and reinforced in the physical classroom setting. Therefore, taking a holistic approach to teaching and learning ensures both the physical and technical enhanced virtual learning settings are complimentary and aid in improving students' learning experience.

\section{Conclusion}

The steps taken to improve Moodle's user interface and learners' overall experience was guided by the literature in the field. This paper also reflects on our own personal experience of creating elearning content and designing and maintaining an elearning platform.

The study concluded that making improvements to Moodle can enhance students learning experience. In comparison to the 2015 RCSI Moodle pages, the current Moodle is more in line with the students' needs and caters to a wider range of learners by offering educational videos, podcasts, interactive modules, quizzes, summative and formative assignments, and lecture slides.
Simple and intuitive user interfaces encouraged uptake, and this was evident, as after the Moodle revamp, the uptake vastly increased. Students interacted with more Moodle pages for a longer duration following the Moodle modifications, which were driven by student feedback. Higher student satisfaction levels were reported following improvements made to Moodle. This research can aid educators in enhancing Moodle usage.

On-going assessment and reassessment of student interaction in their VLE leads to greater satisfaction and engagement with the core curriculum. Students interacted with more VLE pages for longer durations following initial large-scale changes. Subsequent VLE modifications were driven by student feedback. Ongoing assessment and reassessment of student interaction with VLE leads to student driven changes.

This quality audit aimed to improve medical students' user experience and create an e-learning environment that helps to prepare them as future doctors. Evaluations were carried out on the pre and post Moodle revamp to gather feedback on the interface and suggest how Moodle users' satisfaction can improve.

The 2018 user reports and student feedback showed greater student satisfaction and high elearning engagement levels. Virtual learning environments can enhance users learning experiences. Prior to our 2015 Moodle revamp the VLE was being underused and in other curriculum areas it still continues to be underutilized.

New technologies and networks can aid in enriching and providing 'greater interactivity within the virtual learning environment'. Virtual learning environments provides many innovative and exciting possibilities for learners, educators and universities [23]. As educators it is important to harness the potential of our Virtual Learning Environment (Moodle).

\section{Declaration}

The authors report no conflicts of interest. The authors alone are responsible for the content and writing of the article.

\section{References}

[1] Ruiz, J. G., Mintzer, M. J., \& Leipzig, R. M. (2006). The impact of e-learning in medical education. Academic medicine, 81(3), 207-212.

[2] Z. Sozgun, Z. Altinay, M. Berigel, H. Karal and F. Altinay (2018) "A practice of e-learning platform in fostering professional development.” Qual Quant (2018) 52: S79-S92. https://doi.org/10.1007/s11135-017-0589-1

[3] A. Kok, (2010). "C-Thinking via E-learning: A Conceptual Paper about the Use of Digital Learning Tools 
for Reflective Thinking" University of Oxford, International Journal of Digital Society (IJDS), Volume 1, Issue 1, March 2010

[4] Lumsden, C. J., Byrne-Davis, L. M. T., Mooney, J. S., \& Sandars, J. (2015). "Using mobile devices for teaching and learning in clinical medicine."

[5] Kanuka, H., \& Garrison, D. R. (2004). Cognitive presence in online learning. Journal of Computing in Higher Education, 15(2), 21.

[6] M.D. Sorcinelli, A.E. Austin, P.L. Eddy and A.L. Beach (2006) "Creating the Future of Faculty Development: Learning from the Past, Understanding the Present.” Anker Publishing Company Inc., Bolton

[7] K.P. King and P.A. Lawler (2003) "New Perspectives on Designing and Implementing Professional Development of Teachers of Adults." New Directions for Adult and Continuing Education, vol. 98. Jossey-Bass, San Francisco

[8] J. Boulton (2002). Web-Based Distance Education: Pedagogy, Epistemology, and Instructional Design.

[9] Department of Education and Skills (2011). "National Strategy for Higher Education to 2030: Report of the Strategy Group.” Ireland: Dublin, January 2011.

[10] M.B. Postholm (2008). "Cultural historical activity theory and Dewey's idea-based social constructivism: consequences for educational research." Crit. Soc. Stud. 1, $37-48$.

[11] Tham, Chee M., Werner, Jon M. (2005) "Designing and evaluating e-learning in higher education: a review and recommendations.” J. Leadersh. Organ. Stud. 11, 15-25.

[12] Chodorow S. Educators must take the electronic revolution seriously. Acad Med. 1996; 71:221-26

[13] V. Moreno, F. Cavazotte and Alves, I. (2017). "Explaining university students' effective use of e-learning Platforms." British Journal of Educational Technology Vol 48 No 4, 2017, pp. 995-1009, doi:10.1111/bjet.12469

[14] Valentine, D. (2002). "Distance learning: promises, problems, and possibilities." Online J. Distance Learn. Adm. 5(3).

[15] Rosenberg M. E-Learning: Strategies for Delivering Knowledge in the Digital Age. New York: McGraw-Hill, 2001.

[16] Brandl, Klaus. "Are you ready to Moodle." Language Learning \& Technology 9.2 (2005): 16-23.

[17] J.M. Yates (2003) "Interactive Distance Learning in Prek-12 Settings." Greenwood Publishing, Westport.

[18] M.C. Lohman (2000) "Environmental inhibitors to informal learning in the workplace: a case study of publicschool teachers.” Adult Educ. Q. 50(2), 83-101.
[19] A.W. Bates, (2000). "Managing Technological Change: Strategies for College and University Leaders." Jossey-Bass, San Francisco.

[20] R. Rezabek, (1999). "A Study of the Motives, Barriers, and Enablers Affecting Participation in Adult Distance Education Classes in an Iowa Community College.” ERIC Document Reproduction Service.

[21] J.W. Creswell (2003) "Research Design: Qualitative and Quantitative Approaches." SAGE, London.

[22] S. Barzegar, M. Shojafar and M.R. Keyvanpour (2010) "Improvement User Interface in Virtual Learning Environment" International Journal of Digital Society (IJDS), Volume 1, Issue 3, September 2010.

[23] J. Haber and M. Mills (2008) "Perceptions of barriers concerning effective online teaching and policies." Commun.Coll. J. Res. Pract. 32, 266-283.

[24] Kluger, A. N., \& Van Dijk, D. (2010). Feedback, the various tasks of the doctor, and the feedforward alternative. Medical education, 44(12), 1166-1174.

[25] Ferreri, S., and O'Connor (2013). "Instructional design and assessment. Redesign of a large lecture course into a small-group learning course." American Journal of Pharmaceutical Education, 77(1), 1-9.

[26] Sharma, N., Lau, C. S., Doherty, I., \& Harbutt, D. (2015). "How we flipped the medical classroom". Medical teacher, 37(4), pp.327-330.

[27] Kanimozhi. (2018). "VIRTUAL LEARNING ENVIRONMENT", International Journal of Advanced Research in Computer Science, Volume 9, Special Issue No. 1, February 2018, Available Online at www.ijarcs.info.

[28] Wentling T, Waight C, Gallaher J, La Fleur J, Wang C, Kanfer A. (2000) "E-Learning: A Review of Literature" http://learning.ncsa.uiuc.edu/ papers/elearnlit.pdf. University of Illinois National Center for Supercomputer Applications, UrbanaChampaign, IL. 